(2) Open Access Full Text Article

\title{
Impact of bronchiectasis on the frequency and severity of respiratory exacerbations in COPD
}

This article was published in the following Dove Press journal: International Journal of COPD

\author{
Wassim W Labaki \\ MeiLan K Han \\ Division of Pulmonary and Critical \\ Care Medicine, University of Michigan \\ Health System, Ann Arbor, MI, USA
}

\section{Dear editor}

In a recent issue of the International Journal of Chronic Obstructive Pulmonary Disease, Kawamatawong et al reported an association between chest CT-detected bronchiectasis and frequent or severe respiratory exacerbations in 72 Thai patients with COPD (adjusted odds ratio [OR] 4.99; 95\% CI 1.31-18.94; $p=0.018$ ). ${ }^{1}$ Frequent exacerbations were defined as two or more events per year, and severe ones as those requiring hospitalization. The results of this study are consistent with those previously reported by Martínez-García et al who found bronchiectasis to be independently associated with severe COPD exacerbations in 92 subjects (OR 3.07; 95\% CI 1.07-8.77; $p=0.037) .^{2}$

While the prevalence of bronchiectasis in individuals with COPD varies depending on the selected cohort, it is increasingly recognized as a major contributor to COPD morbidity and mortality. ${ }^{3}$ This contribution is better understood by assessing epidemiological measures of impact such as the population-attributable risk percent (PAR\%) and the attributable risk percent (AR\%). ${ }^{4}$ The PAR\% calculated based on Table 1, which was constructed using data from the study by Kawamatawong et al, is $28.3 \%$. If we assume a causal relationship between the presence of bronchiectasis and respiratory exacerbations, this would mean that $28.3 \%$ of respiratory exacerbations in this entire COPD cohort can be attributed to bronchiectasis. The calculated AR\% is $45.4 \%$, meaning that $45.4 \%$ of respiratory exacerbations in COPD patients with bronchiectasis can be attributed to their bronchiectasis.

These $\mathrm{PAR} \%$ and $\mathrm{AR} \%$ measures suggest a relatively high impact of bronchiectasis on the frequency and severity of respiratory exacerbations in COPD. Similarly, severe and recurrent exacerbations may also themselves contribute to the incidence or worsening of bronchiectasis. However, clinical data on patients with coexisting COPD and bronchiectasis are scarce as obtaining a chest $\mathrm{CT}$ is not currently part of routine care for COPD. In addition, the role of targeted bronchiectasis therapy (such as inhaled antibiotics, prolonged intravenous antibiotics, mucolytic agents and high-frequency

Table I Number of severe/frequent COPD exacerbations in patients with and without bronchiectasis

\begin{tabular}{llll}
\hline & $\begin{array}{l}\text { Severe/frequent } \\
\text { COPD exacerbations }\end{array}$ & $\begin{array}{l}\text { No severe/frequent } \\
\text { COPD exacerbations }\end{array}$ & Total \\
\hline CT-detected bronchiectasis & 18 & 16 & 34 \\
No CT-detected bronchiectasis & $1 \mathrm{I}$ & 27 & 38 \\
Total & 29 & 43 & 72 \\
\hline
\end{tabular}


chest wall oscillation) in this COPD/bronchiectasis overlap phenotype still needs to be determined..$^{5}$ These knowledge gaps emphasize the importance of enrolling such patients into dedicated clinical trials to identify best management practices and improve outcomes.

\section{Acknowledgment}

This communication was supported by the US National Institutes of Health grant K24 HL138188.

\section{Disclosure}

$\mathrm{MKH}$ reports consulting for Boehringer Ingelheim, GlaxoSmithKline and AstraZeneca, and research support from Novartis and Sunovion. WWL reports no conflicts of interest in this work.

\section{References}

1. Kawamatawong T, Onnipa J, Suwatanapongched T. Relationship between the presence of bronchiectasis and acute exacerbation in Thai COPD patients. Int J Chron Obstruct Pulmon Dis. 2018;13:761-769.

2. Martínez-García MÁ, Soler-Cataluña JJ, Donat Sanz Y, et al. Factors associated with bronchiectasis in patients with COPD. Chest. 2011; 140(5):1130-1137.

3. Martinez-García MA, de la Rosa Carrillo D, Soler-Cataluña JJ, et al. Prognostic value of bronchiectasis in patients with moderate-to-severe chronic obstructive pulmonary disease. Am J Respir Crit Care Med. 2013;187(8):823-831.

4. Kleinbaum DG, Kupper LL, Morgenstern H. Epidemiologic Research: Principles and Quantitative Methods. Belmont, CA: Lifetime Learning Publications; 1982.

5. O'Donnell AE. Bronchiectasis in patients with COPD: a distinct COPD phenotype? Chest. 2011;140(5):1107-1108. 


\section{Authors' reply}

Theerasuk Kawamatawong'

Jitsupa Onnipa'

Thitiporn Suwatanapongched ${ }^{2}$

'Department of Medicine, Ramathibodi Hospital, Mahidol University, Bangkok, Thailand; ${ }^{2}$ Department of Diagnostic and

Therapeutic Radiology, Ramathibodi Hospital, Mahidol University, Bangkok, Thailand

Correspondence: Theerasuk Kawamatawong

Department of Medicine, Ramathibodi Hospital, Mahidol University,

Rama 6 Road, Phayathai, Rachathewi District, Bangkok 10400, Thailand

Tel +6622011619

Fax +6622011629

Email ktheerasuk@hotmail.com

\section{Dear editor}

We thank Labaki and Han for their comments on our recent study. Calculation of frequent exacerbation risk of the entire COPD cohort was shown in the contingency table. The increased frequency of exacerbation in patients with CT-detected bronchiectasis compared to those with COPD without bronchiectasis was noted. Hence, population-attributable risk percent and attributable risk percent for COPD exacerbation were $28.3 \%$ and $45.4 \%$, respectively. This finding emphasizes the risk of poor COPD outcome in the presence of bronchiectasis. A previous report by Hurst et al showed that both the frequency of exacerbation and hospitalized exacerbation were increased in the presence of bronchiectasis, according to Global Initiative for Chronic Obstructive Lung Disease (GOLD) stages. ${ }^{1}$ Likewise, severe airflow limitation (forced expiratory volume in one second $\left[\mathrm{FEV}_{1}\right]<50 \%$ ) was associated with frequent exacerbation $(p=0.002)$ in the study by Kawamatawong et al. ${ }^{2}$ Despite that bronchiectasis is independently associated with frequent COPD exacerbation, the difference in lung function impairment between COPD patients with and without bronchiectasis was not detected. According to the study by Martínez-García et al, the prevalence of bronchiectasis was high among those with severe COPD compared to those with moderate disease $(p=0.001)$. In addition, hospitalized exacerbation was independently associated with bronchiectasis. ${ }^{3}$ Bronchiectasis worsened by COPD exacerbation is associated with aging, pathogenic bacterial airway colonization and severe systemic inflammation. ${ }^{4}$ Both COPD and bronchiectasis are considered different disease entities but can coexist. ${ }^{5}$ Effective treatment for coexisting bronchiectasis and COPD has never been studied. The treatments of adults with bronchiectasis including long-term macrolide and aerosolized antibiotics and airway clearance have been addressed. ${ }^{6}$ Macrolide therapy has been shown to effectively prevent COPD exacerbation. ${ }^{7}$ Hence, it has been recommended for high-risk and symptomatic COPD. However, occult mycobacterial infection and macrolideresistant pathogens have been reported. The prevalence of mycobacterial infection among COPD patients in our cohort and another study was low. ${ }^{8}$ Mycobacterium screening prior to starting macrolide is not routine. $\mathrm{N}$-acetyl cysteine has been investigated in COPD. ${ }^{9}$ Studies examining the efficacy of $\mathrm{N}$-acetyl cysteine on COPD with bronchiectasis are limited. In addition, roflumilast has been shown to be effective in severe COPD associated with frequent exacerbations and chronic bronchitis. ${ }^{10}$ Evidence demonstrating the efficacy of roflumilast on bronchiectasis is limited. ${ }^{11}$

In summary, the CT-detected bronchiectasis is associated with frequent COPD exacerbations. The potential mechanistic links and causality have to be further elucidated. Lastly, effective treatments for bronchiectasis coexisting with COPD are urgently required.

\section{Disclosure}

The authors report no conflicts of interest in this communication.

\section{References}

1. Hurst JR, Vestbo J, Anzueto A, et al; Evaluation of COPD Longitudinally to Identify Predictive Surrogate Endpoints (ECLIPSE) Investigators. Susceptibility to exacerbation in chronic obstructive pulmonary disease. N Engl J Med. 2010;363(12):1128-1138.

2. Kawamatawong T, Onnipa J, Suwatanapongched T. Relationship between the presence of bronchiectasis and acute exacerbation in Thai COPD patients. Int J Chron Obstruct Pulmon Dis. 2018;13:761-769.

3. Martínez-García MA, Soler-Cataluña JJ, Donat Sanz Y, et al. Factors associated with bronchiectasis in patients with COPD. Chest. 2011; 140(5):1130-1137.

4. Ni Y, Shi G, Yu Y, Hao J, Chen T, Song H. Clinical characteristics of patients with chronic obstructive pulmonary disease with comorbid bronchiectasis: a systemic review and meta-analysis. Int J Chron Obstruct Pulmon Dis. 2015;10:1465-1475.

5. Novosad SA, Barker AF. Chronic obstructive pulmonary disease and bronchiectasis. Curr Opin Pulm Med. 2013;19(2):133-139.

6. Chalmers JD, Aliberti S, Blasi F. Management of bronchiectasis in adults. Eur Respir J. 2015;45(5):1446-1462.

7. Albert RK, Connett J, Bailey WC, et al; COPD Clinical Research Network. Azithromycin for prevention of exacerbations of COPD. $N$ Engl J Med. 2011;365(8):689-698.

8. Palwatwichai A, Chaoprasong C, Vattanathum A, Wongsa A, Jatakanon A. Clinical, laboratory findings and microbiologic characterization of bronchiectasis in Thai patients. Respirology. 2002;7(1):63-66.

9. Decramer M, Rutten-van Mölken M, Dekhuijzen PN, et al. Effects of $\mathrm{N}$-acetylcysteine on outcomes in chronic obstructive pulmonary disease (Bronchitis Randomized on NAC Cost-Utility Study, BRONCUS): a randomised placebo-controlled trial. Lancet. 2005; 365(9470):1552-1560.

10. Rennard SI, Calverley PM, Goehring UM, Bredenbroker D, Martinez FJ. Reduction of exacerbations by the PDE4 inhibitor roflumilast - the importance of defining different subsets of patients with COPD. Respir Res. 2011;12:18.

11. Kawamatawong T. Roles of roflumilast, a selective phosphodiesterase 4 inhibitor, in airway diseases. J Thorac Dis. 2017;9(4):1144-1154. 
Dove Medical Press encourages responsible, free and frank academic debate. The content of the International Journal of Chronic Obstructive Pulmonary Disease 'letters to the editor' section does not necessarily represent the views of Dove Medical Press, its officers, agents, employees, related entities or the International Journal of Chronic Obstructive Pulmonary Disease editors. While all reasonable steps have been taken to confirm the content of each letter, Dove Medical Press accepts no liability in respect of the content of any letter, nor is it responsible for the content and accuracy of any letter to the editor.

International Journal of COPD

\section{Publish your work in this journal}

The International Journal of COPD is an international, peer-reviewed journal of therapeutics and pharmacology focusing on concise rapid reporting of clinical studies and reviews in COPD. Special focus is given to the pathophysiological processes underlying the disease, intervention programs, patient focused education, and self management protocols.

Dovepress

Submit your manuscript here: http://www.dovepress.com/international-journal-of-chronic-obstructive-pulmonary-disease-journal

This journal is indexed on PubMed Central, MedLine and CAS. The manuscript management system is completely online and includes a very quick and fair peer-review system, which is all easy to use. Visit $\mathrm{http}: / / \mathrm{www}$.dovepress.com/testimonials.php to read real quotes from published authors. 